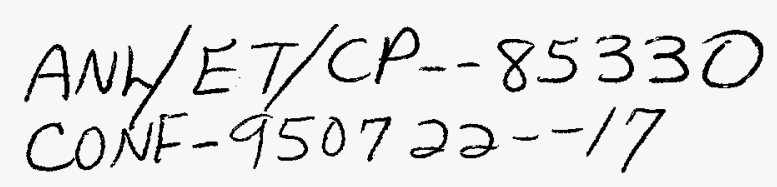

\title{
FABRICATION OF SUPERCONDUCTING JOINTS FOR Ag-CLAD BSCCO CONDUCTORS ${ }^{*}$
}

\author{
A. N. Iyer, J. Y. Huang, R. Jammy, and U. Balachandran \\ Energy Technology Division \\ Argonne National Laboratory \\ Argonne, IL 60439
}

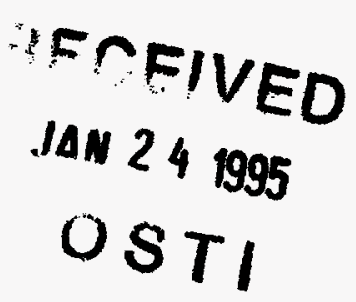

\author{
P. Haldar \\ Intermagnetics General Corporation \\ Latham, NY 12110
}

July 1995

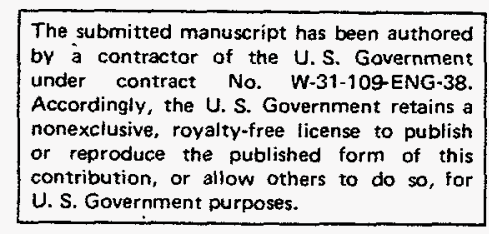

\section{DISCLAIMER}

\begin{abstract}
This report was prepared as an account of work sponsored by an agency of the United States Government. Neither the United States Government nor any agency thereof, nor any of their employees, makes any warranty, express or implied, or assumes any legal liability or responsibility for the accuracy, completeness, or usefulness of any information, apparatus, product, or process disclosed, or represents that its use would not infringe privately owned rights. Reference herein to any specific commercial product, process, or service by trade name, trademark, manufacturer, or otherwise does not necessarily constitute or imply its endorsement, recommendation, or favoring by the United States Government or any agency thereof. The views and opinions of authors expressed herein do not necessarily state or reflect those of the United States Government or any agency thereof.
\end{abstract}

Manuscript submitted for publication in Advances in Cryogenic Engineering, Volume 42, 1995.

*Work at ANL and part of the work at IGC is supported by the U.S. Department of Energy (DOE), Energy Efficiency and Renewable Energy, as part of a DOE program to develop electric power technology, under Contract W-31-109-Eng-38. 


\section{DISCLAMMER}

Portions of this document may be illegible in electronic image products. Images are produced from the best available original document. 


\title{
FABRICATION OF SUPERCONDUCTING JOINTS FOR Ag-CLAD BSCCO CONDUCTORS
}

\author{
A. N. Iyer, J. Y. Huang, R. Jammy, U. Balachandran 1 , P. Haldar, and J. G. \\ Hoehn, Jr. ${ }^{2}$ \\ ${ }^{1}$ Energy Technology Division, Argonne National Laboratory \\ Argonne, IL 60439, U.S.A. \\ 2 Intermagnetics General Corporation * \\ Latham, NY 12110
}

\begin{abstract}
Potential applications of high- $T_{c}$ superconductors include motors, generators, transmission cables, magnets, etc. At present, resistive connections are used to connect various high- $T_{c}$ components for such applications. However, to improve efficiency, it is imperative that the resistive connection be replaced by a true superconducting joint. Using a novel etching technique, we have fabricated superconducting lap and butt joints between Ag-clad BSCCO conductors. The Ag sheath from one side of the tape was selectively etched to expose the underlying superconductor core. Joints were formed by bringing the two tapes together and heat treating them. Detailed microstructural analysis and current transport measurements of the joints have been performed. Critical current $\left(I_{c}\right)$ through a monofilament lap- and butt-joint were 10 and $23 \mathrm{~A}$, respectively. $\mathrm{I}_{\mathrm{c}}$ within the joint for mono- and multifilament conductors were 37 and $21 \mathrm{~A}$, respectively. Additionally, effects of various joint configurations, processing techniques, and strain on the transport property of the joint are also being studied.
\end{abstract}

\section{INTRODUCTION}

Considerable progress has been made in the development of high-criticaltemperature (high- $\mathrm{T}_{\mathrm{c}}$ ) bismuth-strontium-calcium-copper-oxide (BSCCO) superconductors by the powder-in-tube (PIT) technique. Two important parameters, critical current density $\left(J_{c}\right)$ and conductor length, have steadily improved since the first application of this technique to high- $\mathrm{T}_{\mathrm{c}}$ materials. $\mathrm{J}_{\mathrm{c}}$ values as high as $\approx 1.2 \times 10^{4} \mathrm{~A} / \mathrm{cm}^{2}$ have been obtained in a 125 -m-long monocore and an 850 -m-long 37 -filament conductor. ${ }^{1-7}$

The long-length conductors have been fabricated into pancake-shaped coils, and high- $T_{c}$ magnets have been assembled from them for use in applications such as motors, generators, and medical diagnostic equipments such as that used in magnetic resonance imaging. ${ }^{1-3,5,8}$ At present, resistive interconnections are used to join high-quality short- or medium-length conductors for coil winding and for interconnecting various parts of a superconducting device. Because the resultant Joule heating is undesirablc, and the 
Silver Sheath
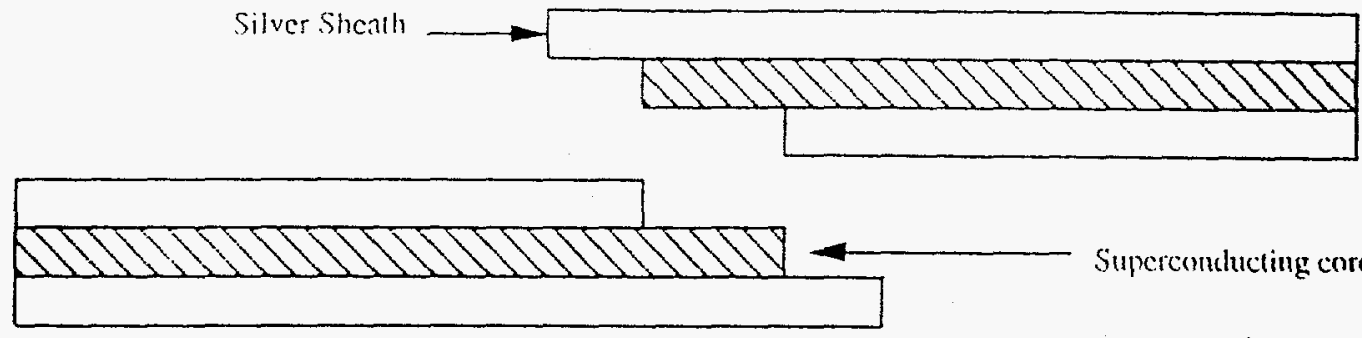

Superconducting core

Lap joint

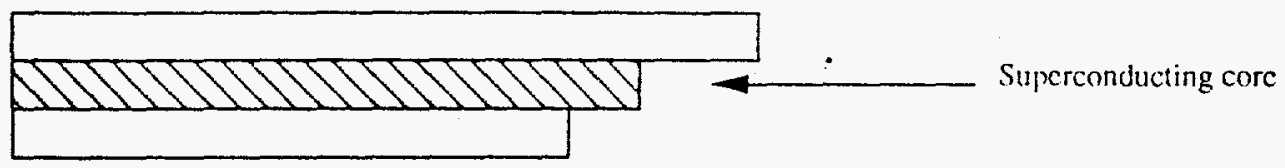

Silver Slicath

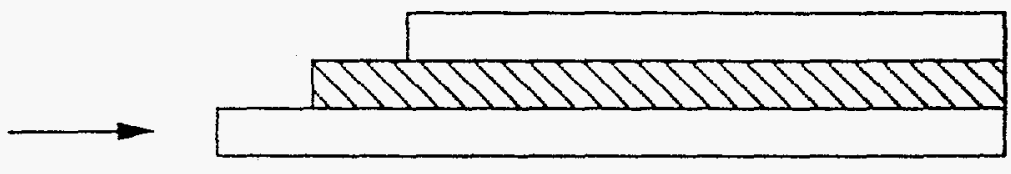

Butt joint

Figure 1. Schematic representation of joint formation.
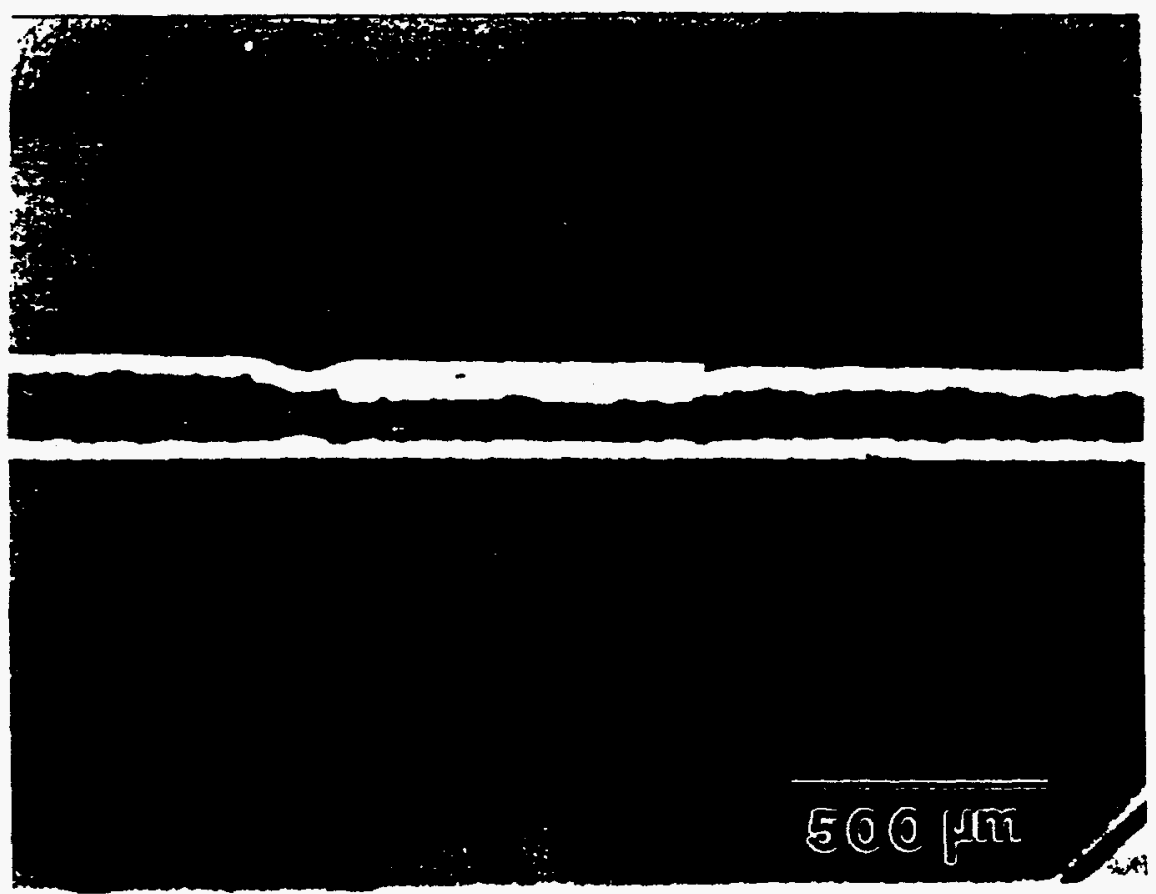

Figure 2. Longitudinal cross scction of lap joint, illustrating threc distinct joined, transition, and unjoincd regions. 
$I_{c}$ as a function of heat-treatmene time for the lap joint and normal tape is shown in Figure 5 . Initially, $I_{c}$ of the joined tape is low because of incomplete formation of the joint. After $250 \mathrm{~h}$ of thermomechanical treatment, typical $\mathrm{I}_{\mathrm{c}}$ within and through the lap joint was 37 and $10 \mathrm{~A}$, respectively. In comparison, $\mathrm{I}_{\mathrm{c}}$ of a normal tape (heat treated simultaneously) was 31 A. The difference in $I_{c}$ through and within the joint can be attributed to the difference in thickness between the joined and unjoined regions of the tape uniaxial pressing, the thickness difference causes nonuniform distribution or stresses. Because the joined region suffers more reduction than the unjoined region, the transition region between the two becomes sheared. Large transverse microcracks (Figure 6 ) are formed in the transition region. This in turn results in degradation of current transport through the joint.
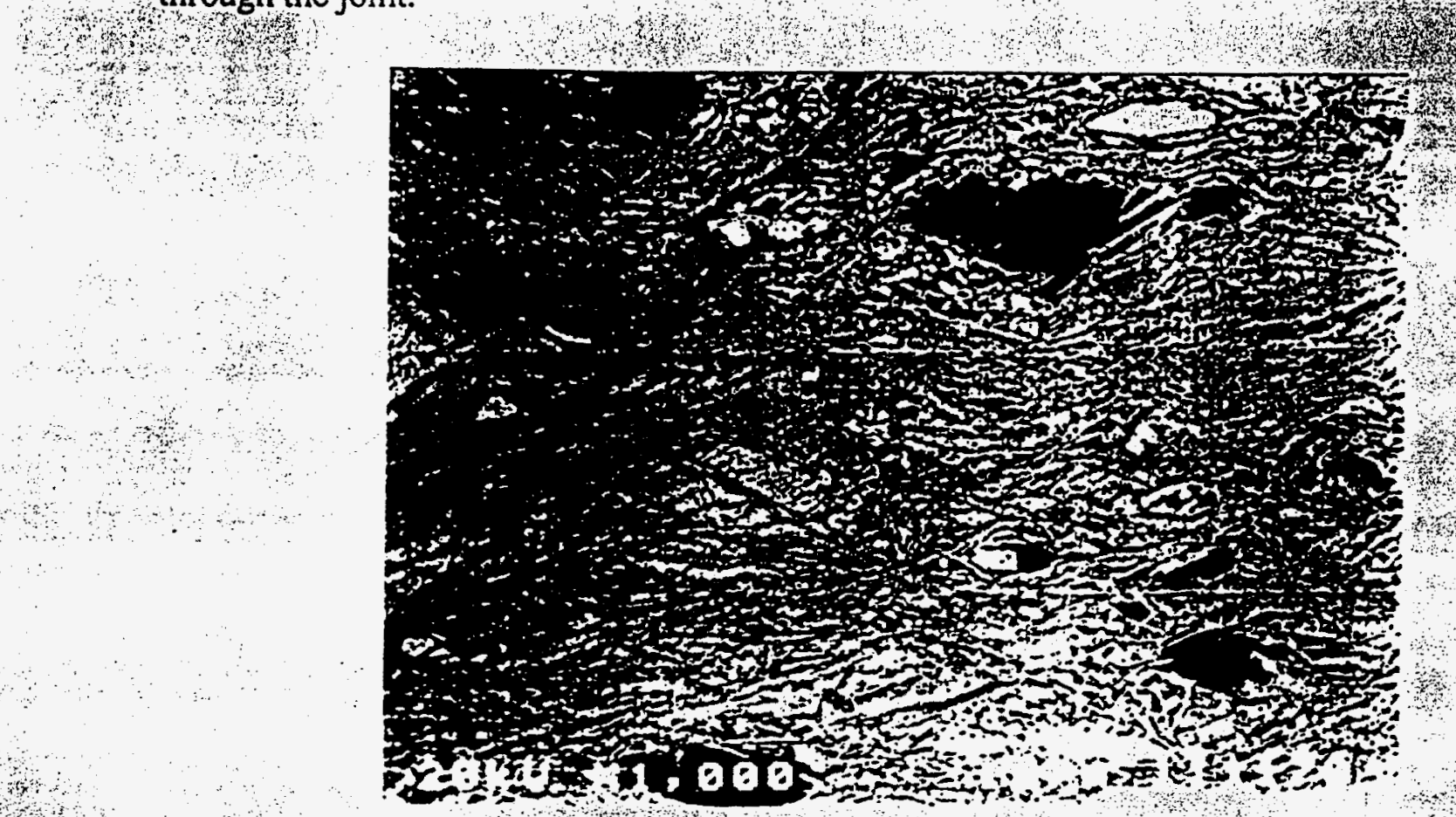

(a)

(n)




\section{REFERENCES}

1. K. Sato, T. Hikata, H. Mukai, M. Ucyama, N. Shibuta. T. Kato, T. Masuda, M. Nagata, K. Iwata. and T. Mitsui, IEEE Trans. Magn. 27:1231 (1991).

2. S. X. Dou, Y. C. Guo, J. Yau, and H. K. Liu, Supercond. Sci. Teclmol. 6:195 (1993).

3. U. Balachandran. A. N. Iyer, J. Y. Huang, R. Jammy, P. Haldar, J. G. Hochn, Jr, G. Galinski, and L. R. Motowidlo, J. Metals 46:23 (1994).

4. U. Balachandran, A. N. Iyer, P. Haldar, J. G. Hoehn, Jr., L. R. Motowidlo and G. Galinski. Appl. Supercond. 2:251 (1994).

5. J. Schwartz, J. K. Heuer, K. C. Gorella, R. B. Poeppel, J. Guo and G. W. Raban, Ir., Appl. Supercond. 2:271 (1994).

6 M. Lelovic, P. Krishnaraj, N. G. Eror. and U. Balachandran, Physica C 242:246 (1995).

7. D. C. Larbaleister, X. Y. Cai, Y. Feng, H. Edelman, A. Umezawa, G. N. Riley, Jr., and W. L. Carter. Physica C 221:299 (1993).

8. J. W. Bray, Appl. Supercond. 2:149 (1994).

9. M. G. Benz, L. E. Rumaner, B. A. Knudsen, R. J. Zabala and H. R. Hart. J. Mag. Marls. 22:1299 (1993).

10. J. Cai, X. M. Xie, L. Baoshun, X. X. Huang, T. G. Chen and J. K. Guo, Supercond. Sci. Techmol. 5:599 (1992)

11. M. A. Hilal, X. Huang and J. D. Lloyd, IEEE Trans. Magn. 27:927 (1991).

12. Y. Mutoh, M. Inoue and T. Konatsu, Jpn. J. Appl. Phys. 29:L1432 (1990).

13. J. E. Tkaczyk, R. H. Arendt, P. J. Bednarcyzk, M. F. Garbauskas, B. A. Jones, R. J. Kilmer and K. W. Lay, IEEE Trans. Appl. Supercond. 3:946 (1993).

14. K. Shibutani, T. Egi, S. Hayashi, Y. Fukumoto, I. Shigaki, Y. Masuda, R. Ogawa and Y. Kawatc, IEEE, Trans. Appl. Supercond. 3:935 (1993).

15. "CRC Handbook of Metal Etchants". P. Walker and W. H. Tarn, eds., CRC Press, Inc. Boca Raton, MI. (1991).

16. G. F. Vander Voort, "Metallography Principles and Practice", A. Murphy and Susan Hazlell, cds.. McGraw-Hill, New York, (1984). 